\title{
SURINAAMSCHE GENEESKRUIDEN IN DE TIJD VAN LINNAEUS
}

DOoR

\author{
DR. J. LANJOUW EN DR. H. UITTIEN
}

$\mathrm{Nu}$ Linnaeus weer eens in het centrum van de belangstelling staat, dank zij het feit, dat het dit jaar twee eeuwen geleden is, sinds hij te Harderwijk promoveerde, zij het ons vergund nog eens de aandacht te vestigen op de invloed, die de groote hervormer der plantensystematiek heeft gehad op het botanisch onderzoek van Suriname, waar de eerste verzamelingen van planten door twee zijner leerlingen, Daniel Rolander, een Deen, en Carl Gustaf Dahlberg, een Zweed, werden aangelegd. Vergeefs had Boerhaave getracht, Linnaeus, tijdens zijn verblijf in Leiden, te overreden de betrekking van gouvernementsarts in Suriname te aanvaarden, en kort daarop waren twee van Linnaeus' leerlingen in deze functie uitgezonden, maar beiden stierven spoedig na hun aankomst, zoodat we hen, Johann Bartsch en Tiburtius Kiellman, zwijgend kunnen voorbijgaan. De resultaten van Rolanders reis waren al heel gering. Hij stuurde een cactus met cochenille-luizen, die de tuinman, nog vóór Linnaeus ze gezien had, grondig uitroeide, en gaf de rest van zijn verzamelingen aan anderen. Een tiental Cyperaceeën, door hem verzameld, werden in 1773 door Rottboell beschreven. Belangrijker was de collectie van Dahlberg, die de stof leverde voor de dissertatie van Jacobus Alm, getiteld Plantae surinamenses, in 1775 verschenen. Een manuscript uit de bibliotheek van de Linnean Society werpt hier een nieuw licht op en was de aanleiding tot het schrijven van dit artikel.

Tijdens een bezoek aan het Natural History Museum te Londen vestigde het vorig jaar de directeur van de Botanische Afdeeling, Dr. J. Ramsbottom, onze aandacht op een in het Nederlandsch geschreven manuscript van de Zweed Carl Gustaf Dahlberg, handelend over een collectie planten, die hij naar Europa 
had gezonden. Door de welwillendheid van Dr. Ramsbottom en de heer S. Savage, bibliothecaris van de Linnean Society, werden wij in de gelegenheid gesteld dit in te zien en over te schrijven. De copie berust nu in de bibliotheek van het Botanisch Museum en Herbarium te Utrecht. Al spoedig bleek, dat dit de beschrijving was van de planten, die in Alms dissertatie verwerkt zijn. Alm, d.w.z. Linnaeus, want de promovendi van die dagen verkeerden nog in de gelukkige omstandigheid dat de promotor (in dit geval Linnaeus) het proefschrift schreef en zij slechts voor de verdediging en waarschijnlijk de drukkosten behoefden te zorgen, spreekt niet over Dahlberg en vermeldt dus ook het feit niet, dat hij de beschikking had over zoo'n uitvoerig en met groote belangstelling en ijver, zij het ook weinig botanische kennis, geschreven verhandeling. Wel roemt hij de uitstekende toestand, waarin de planten verkeerden, die alle in alcohol bewaard waren, zoodat „ook de kleinste bloemdeelen nauwkeurig onderzocht konden worden, alsof ze aan de levende plant zelf bekeken werden". Het handschrift werpt dus wel een nieuw licht over het ontstaan van deze eerste studie over de Surinaamsche flora. Bovendien verklaart het allerlei kleinigheden, die tot nu toe in het stuk van Alm onbegrijpelijk waren, terwijl het ook interessant is als bijdrage tot de kennis van de merkwaardige figuur van Dahlberg, de ontdekker van het kwassiehout, die als naamloos korporaal met enkele stuivers op zak in Suriname aankwam, al spoedig opklom tot sous-lieutenant der artillerie, een weduwe trouwde, die hem twee plantages aanbracht, Raad van Policie en crimineele Justitie werd en zich de weelde veroorloven kon, drie maal een reis naar $Z$ weden te maken, en de beide laatste keeren zelfs bijna of ruim vier jaren afwezig te blijven. Stedman haalt hem in zijn Reize naar Surinamen IV (1800), p. 6 dan ook aan als een voorbeeld van de groote weelde en pracht, die er in Suriname heerschten: „de heer d'Ahlberg, die behalve eene goude snuifdoos, met edele gesteenten omzet, en hebbende de waarde van 600 ponden sterlings, mij twee stukjes zilver geld vertoonde, met goude randen, en met diamanten omzet, met dit opschrift: Soli Deo gloria, fortuna beatum etc. Mij niet hebbende kunnen weerhouden, om hem mijne verwondering te kennen te geven, dat hij zoo bijzonder veel werk maakte van twee zulke ligte stukjes, gaf hij mij ten antwoord, dat dit al het gereed geld was, het welk hij bezat, toen hij uit zijn vaderland, Zweden, in deeze Volkplanting kwam. Werkte gij? zeide ik hem. - Neen - Vroeg gij om een aalmoes? — Neen. - Gij hebt evenwel niet gestolen? 
- Neen; maar, onder ons, ik gedroeg mij als een geestdrijver; het geen nu en dan zeer noodzakelijk is, en de drie andere kostwinningen overtreft". Dat hij dan ook "meer benijt dan beklaghet" werd, blijkt wel uit de verschillende lasterpraatjes, die over hem werden rondgestrooid. Het proces over de zoogenaamde vernieling van het huis van Kwassie vindt men met heel veel andere bijzonderheden, zoowel over Dahlberg als Kwassie, in het artikel van Dr. Sack in het Pharmaceutisch Weekblad van 1911, p. 1152-1157 en 1175-1186, getiteld: Mededeelingen over den ontdekker van het Quassiehout. Het verhaal van de weggeloopen neger Baron staat in Stedman, deel I, p. 117 van de Nederlandsche vertaling en ,het einde van de legende" kan men in het elfde deel van dit tijdschrift, p. 165-167 lezen.

Over Dahlberg zelf kunnen we dus kort zijn. In 1754 ging hij voor de eerste keer naar Zweden terug, waar hij kennis maakte met Linnaeus, die hem om gastvrijheid verzocht voor zijn leerling Rolander, die dan ook hetzelfde jaar nog met hem meegaat. De brief, die Dahlberg op 18 Januari 1755 uit Amsterdam aan Linnaeus schreef, bevat, behalve de mededeeling, dat ze na een reis door Duitschland veilig samen in Amsterdam zijn aangekomen en op de eerste gunstige wind wachten om weg te zeilen, het verzoek, dat Linnaeus hem in ruil voor zijn moeite de „kleine” eer zal aandoen, zijn naam voor het nageslacht te bewaren. Alles, wat hij zal kunnen verzamelen, zal hij aan Linnaeus sturen. Linnaeus heeft later deze wensch vervuld en een geslacht der Leguminosen ter eere van de broers Nils en Carl Gustaf Dahlberg Dalbergia genoemd. De $\mathrm{h}$ is weggelaten, omdat de andere broer zijn naam zonder die letter placht te schrijven. 21 Juni 1755 kwamen ze in Paramaribo aan. Een tweede brief, op 20 Januari 1756 geschreven en evenals de bovengenoemde thans in het bezit van de Linnean Society te Londen (beide zijn afgedrukt in de uitgave van de brieven van Linnaeus, door de universiteit te Upsala uitgegeven; Förste Afdeln. Del V, Stockholm 1911, p. 319), schrijft uitvoeriger over Rolander, die na zes maanden verblijf het niet langer uithield, omdat hij niet tegen het klimaat kon. Dahlberg had nog getracht hem langer te houden, vooral ook om de gebergteflora te bestudeeren. Maar Rolander vond, dat hij het meeste wel gezien had en dat de rijkdom van de natuur erg tegenviel.

Juni 1761 gaat Dahlberg voor de tweede maal naar Zweden, ditmaal met vrouw en kinderen. Bij deze gelegenheid geeft hij Linnaeus het kwassiehout, waarop deze in 1763 een van zijn leer- 
lingen laat promoveeren. De dissertatie verscheen in het Latijn in de Amoenitates Academiae VI, p. 416 en het volgend jaar in het Nederlandsch in de Verhandelingen van de Societeit der Wetenschappen te Amsterdam, onder de titel: C. M. Blom, Het quassiehout uit Suriname als koortsmiddel. Men vindt de geschiedenis hiervan uitvoerig in het boven aangehaalde artikel van Dr. Sack. Eveneens in het Handbuch der Pharmacognosie van Tschirch, deel III, 2 (1925), p. 789, zij het dan ook vermeerderd met een drietal fouten, die waarschijnlijk voor een groot deel op onvoldoende kennis van het Nederlandsch berusten. Waarschijnlijk heeft Dahlberg bij zijn derde reis naar het vaderland (11 Mei 1771 tot 9 Juli 1775) de in alcohol geconserveerde verzameling meegebracht, waarop ons handschrift betrekking heeft. Koning Gustaf III, die een groote bewondering voor Linnaeus had en hem, toen hij nog kroonprins was, zelfs met een bezoek aan zijn buitenhuis in Hammarby had vereerd, schonk hem met Kerstmis 1774 de verzameling van Dahlberg. Linnaeus, die kort tevoren door een lichte beroerte was getroffen en zwak en zonder werklust te bed lag, kreeg door de vreugde over deze nieuwe en prachtige collectie - de eerste tropische verzameling, die op alcohol geconserveerd hem bereikte! - nieuwe energie. Hij verliet onmiddellijk het ziekbed om de ongeveer 180 soorten te bestudeeren en te beschrijven. Zijn leerling Jacobus Alm promoveerde er 23 Juni van het volgende jaar op. Dahlberg was toen al weer op de terugreis naar Suriname. Hoewel het boekje dus Alm als auteursnaam draagt, wordt het in de literatuur zeer terecht steeds als van Linnaeus afkomstig geciteerd. Het bevat alleen zeer korte diagnosen, behalve een van de nieuwe geslachten, dat uit dankbaarheid naar den schenker Gustavia genoemd werd en uitvoeriger beschreven is.

De planten van Dahlberg zijn hoogstwaarschijnlijk verloren gegaan. In het herbarium van Linnaeus in de Linnean Society te Londen zijn ze niet. Aanvankelijk hadden wij nog hoop, dat de verzameling te Upsala te vinden zou zijn. Vorige zomer hebben wij op een reis naar Zweden daartoe Upsala aangedaan, maar er is daar niets meer bewaard gebleven van planten in flesschen met alcohol. Wel bevinden zich in het herbarium nog verscheidene gedroogde planten uit Suriname zonder vermelding van de herkomst, zoodat de mogelijkheid nog bestaat, dat Linnaeus of een ander de planten uit de flesschen heeft genomen en daarna gedroogd. Waarschijnlijk is dit echter niet, daar door een langdurig verblijf in alcohol planten meestal te bros zijn geworden om te drogen. 
Om nu op het manuscript terug te komen, dit is getiteld: „Catalogus der Vlessen, van de Boom, Struik, Plant en rankgewassen, dewelke ik, in Spiritus Vini bewaard heb". Het manuscript bevat 156 nummers, waaronder de betreffende planten min of meer uitvoerig worden beschreven en waar bij vele nummers bijzonderheden over het medische of gastronomische nut worden vermeld. Het proefschrift van Alm bevat 177 nummers. Dahlberg heeft ook inderdaad meer nummers verzameld, maar deze niet kunnen beschrijven, daar zijn aanteekeningen hierover verloren zijn geraakt, hetgeen blijkt uit het slot van het geschrift, dat luidt: „Op mijn reys herwards, door Storm \& Stortzee, welke door de Cajuit-Vensters binne sloeg, is mijn Catalogus zo beschadig gebleeven, dat ik de Laatste dertig niet heb kunnen teregt brengen: dog bij aldien deeze genaadig opgenoomen worde \& ik ordre krijge meerder te zaamelen als ook onderrigt worde, op wat voor manier ik de bloeysels beschrijven zal, vinde mij in Staat eenige 100de Sorten meerdere Herbaria te kunnen bezorgen: als ook de Vrugten \& bloeysels welke in deeze manqueeren". Het is met een andere hand en iets donkerder inkt onderteekend: Carl Gustaf Dahlberg. Ook uit een in het zweedsch geschreven brief van Dahlberg blijkt, dat alleen de handteekening door Dahlberg is geschreven en hij dus het handschrift aan iemand moet hebben gedicteerd uit zijn aanteekeningen of dat hij het heeft laten overschrijven. Het is overigens wel vreemd, dat Dahlberg de planten aan den Koning van Zweden heeft gezonden of gegeven met een in het Nederlandsch geschreven catalogus. Dahlberg wist wel dat de planten in handen van Linnaeus zouden komen en heeft mogelijk gedacht dat Linnaeus door zijn langdurig verblijf in de Nederlanden onze taal wel machtig zou zijn. Mogelijk ook is Dahlberg op latere leeftijd door zijn jaren lang verblijf in Suriname aan de Nederlandsche taal de voorkeur gaan geven.

De meeste beschrijvingen van Dahlberg vermelden ook de inlandsche naam van de plant. Deze namen zijn door Linnaeus onderstreept, terwijl hij in de marge de Latijnsche geslachtsnaam heeft geschreven. De herkenning van de hand danken we aan Dr. Savage. Alm, of liever Linnaeus, heeft de volksnamen voor een groot deel overgenomen, terwijl de Latijnsche namen met een soortnaam aangevuld werden, voor zoover dat mogelijk was. De namen waren voor een deel als voorloopig bedoeld, zooals bv. Curcuma nova, Cyperus obscurus, enz. De zoon van Linnaeus schreef in 1781 een aanvulling op zijn vaders levenswerk (Supplementum plantarum, enz.), waarin hij van een groot aantal van 
Dahlbergs planten nieuwe uitvoerige beschrijvingen gaf, meestal onder de naam, die er al door Alm aan gegeven was Het is niet onze bedoeling hier over deze nomenclatuurkwesties te spreken. Slechts enkele opmerkingen over de inlandsche namen en de manier, waarop ze soms door Alm verhaspeld zijn althans in de herdruk van zijn werk, die in 1785 door Schreber bezorgd is en die algemeen verspreid is. De oorspronkelijke uitgave van 1775 hebben we tot nu toe niet kunnen bemachtigen.

Er komen verschillende onbekende en minder algemeene volksnamen in het handschrift van Dahlberg voor, zooals bij voorbeeld Wegloopershaagel voor de zaden van Canna (nr. 21), Sandkookers voor Hura crepitans L., de "possentrie” (nr. 1) zie A. Pulle, Flora of Surinam, deel II, p. 177) en Ducat-beursjes voor Allamanda cathartica L. (nr. 34, zie de flora, deel IV, p. 10), ,werkense bita". Soms zijn die namen, waarschijnlijk wel met de bekende bereidwillige medewerking van het drukfoutenduiveltje, koddig verbasterd. Brada bitta viriviri (nr. 29) of breede bittere bladeren heet bij Alm eenvoudig Brada, wat zinledig is; nr. 43, door Dahlberg Zoeteboontjesboom genoemd (swietieboontjes), werd bij Alm Rote bolties. De zaden van Bombax aquaticum Schum. (nr. 27), zie de flora, deel III, p. 29), die, zooals Dahlberg zegt, „als men de schillen of vlisen afneemt gelijkend na een bijzonder figuur" zijn, noemt hij Sergeants. Waarschijnlijk heeft hij de Surinaamsche geliefde plantennaam Sergeanteklooten opgevangen, die aan de vruchten van de Melastomacee Henriettella Patrisiana Naud. en aan die van Licania macrophylla Bth., een Rosacee, ook wel gegeven worden en kieschheidshalve het tweede deel weggelaten, zooals hij ook de naam Schijtnoten (nr. 70, Jatropha Curcas $L$. , zie de flora, deel II, p. 68) tot Purgatienooten verfraaide. Hoe het zij, bij Alm heet de plant Bergnaut, een naam, waaraan zeker wel niemand, behalve misschien de waarheidlievende verzamelaar van volksnamen, aanstoot zal kunnen nemen. Er is nog iets anders met deze Bombax (nr. 27): Dahlberg schrijft: „N.B. Ik moet deeze wilde Caro noemen, also de vruchten daarna gelijken". Hij bedoelt Wilde Cacao, maar er staat ongeveer Caro. Nu heeft Linnaeus er de Latijnsche geslachtsnaam Sophia bijgezet, later door Alm of hemzelf tot Sophia Carolina aangevuld. De gedachte dringt zich op, dat hij hierbij door het woord Caro geïnspireerd is. De geslachtsnaam Sophia, misschien naar zijn lievelingsdochter, was ongeldig, omdat hij al in 1735 een ander geslacht met die naam had vereerd. De plant kreeg daarom een nieuwe naam Carolinea princeps (prinses Caroline), die pas 
na zijn dood door zijn zoon gepubliceerd werd. Hij gaf die naam ter eere van een bewonderaarster Caroline Louise van Baden Durlach, geboren prinses van Hessen-Darmstadt, die hiermee erg ingenomen was, evenals met een teekening van de plant, die hij haar zond. Haar grootsch opgezette plan om 10.000 platen uit te geven van alle door Linnaeus beschreven planten wilde niet vlotten door de hooge kosten en leed tenslotte door haar vroegtijdige dood geheel schipbreuk. Ook de mooie naam onderging dit lot, want zoowel de naam Pachira als Bombax, tot welk geslacht de plant later bleek te behooren, hebben oudere rechten dan Carolinea.

Uit sommige plaatsen van Alm blijkt, dat hij het Nederlandsch van het handschrift bepaald niet heeft begrepen. Zoo zegt Dahlberg van nr. 83, die hij Sibisibi-viriviri noemt (Sisibi-wiwirie, Scoparia dulcis), „men gebruikt of plant die op de badden in de Tuinen en kan die snoeyen als bosboom", hetgeen Alm, p. 252, vertaalt met: „Pellit bufones ex hortis” (verdrijft de padden uit de tuinen), blijkbaar het woord badden (schrijffout voor bedden?) voor padden aanziende. Ook het recept voor het zweetbad van $\mathrm{nr} .106$, zie beneden, is verkeerd begrepen. In dit geval is Linnaeus Jr. de schuldige: hij maakt er een drankje van.

Hoe angstvallig nauwkeurig de verzamelaar zijn beschrijvingen soms maakte, vooral als het op getallen aankwam, blijkt op vele plaatsen. Bij Bombax, nr. 27, zitten volgens hem ,in ieder koker of vrugt twee en sestig amandelen" en in de bloemen van nr. 131, een Cereus- of Cactussoort, telt hij met een even loffelijke als nuttelooze ijver 601 meeldraden, die hij ,witte hairen met een geel zaatje in 't topeinde van ieder hair" noemt.

Maar het opsommen van alle merkwaardige opmerkingen uit Dahlbergs geschrift zou al te veel plaats vergen. Daarom mogen hier enkel de geneeskruiden volgen. Zoowel om de lezer een juiste indruk van de stijl te geven, alsook om een eventueele identificatie en een vergelijking met tegenwoordig nog bestaande gebruiken mogelijk te maken, zijn alle 26 nummers volledig overgenomen, met behoud van alle eigenaardigheden van de spelling. Daaronder vermeldden wij de Latijnsche naam, die Alm eraan toeschreef, met zoo noodig toevoeging van de nu geldige naam, tegenwoordige volksnaam of andere opmerkingen.

6. Is een plant met blaaderen \& bloeysels; deeze wast wild tot de hoogte van 2 à 3 voeten, de Neegers bruiken ze als zy koorts hebben om zig daarmede te wasschen zy plukken de blaaderen, 
\& vryven dezelve tusschen de handen dan leggen zy dezelve in een tobbe met water \& zet die in de zon om te trekken, warm geworden zynde waschen zy zig daarmeede en worden gezond, de bloeysels zyn witt, verbeeldende een klyn klokje zonder klep, binnen in 't holletje is een klyne prik of stippje, de tak of steel daar de bloeysels aan van booven wascht zitten, is by de 2 duimen van boven krom, zig na beneeden buigende, waarop 30 stuks zolke klyne witte blom-klokkjes aan de bovenkant vast zitten.

Heliotropium indicum $L$. Sack, Bulletin Inspectie van den Landbouw in West Indië. n. 13, 1908, p. 14, vermeldt het gebruik tegen dysenterie.

8. Is de zogenaamde Surinaamsche Thee boom met haare blaaderen, bloeysels \& vrugt of zaaden, deeze is een plant of struik die 6 à 7 voeten hoog groeyt, de bloeysels zijn rood, stootende op blauw, ja zommige zyn geel, de bloeysels zyn verdeeld in 9 stuks, roode \& geele bloemtjes hol van binnen, \& verdeelen zig in 5 deelen van boven; binnen deeze zitten nog 19 uitwassingen met een langwerpige roodagtige knoppje op ieder uitwassing, de blaaderen \& bloeysels worden eerst gedroogt \& daarna gedronken als Thee; is niet alleen lekker van smaak maar teffens considerabel sweetdryvende en heeft een aangenaame reuk.

Lantana Camara L. Koorsoe-wiwirie of Surinaamsche thee. Zie Sack, 1908, p. 14.

9. Is 't plantje Sneki viriviri of Slangengras genoemd, zo als dezelve groeyt met bloeysels \& zaat; dit Plantje heeft een Juffrouw Bosse, welke eene Mulatin was gebruikt te geeven aan de geenen welke de koorts hadden; zy kookte dit kruit in waater $\&$ gaf daarvan 't aftreksel aan den patient te drinken nagt \& dag kommen vol, door welke geneesmiddel veele hunne gezondheid weerom kreegen; maar den Heer Rolander gaf my dit medicament Ao 1755 toen ik met een zeer zwaare Feber geplagt was \& geene andere medicamenten helpen woude; zyn Ed. kookte dit slangengras zolang in waater zo sterk dat 't aftreksel daarvan gelykte aan slappe Coffy \& gaf my daarvan te drinken een Theekoppje 's morgens, middags \& 's avonds drie daagen lang $\&$ de koorts hield op, \& ik God zy dank weeder gezond; men gebruikt dit ook voor de waaterzugt; namentlyk men neemt 2 handen vol van dit slangengras, een onrype ananas een onrype kalbas klyn gesneeden \& daarop een Bottel Madera wyn, \& in de zon gezet om te trekken 24 uuren lang, door gedaan zynde aan den Patient gegeeven 3 maal daags, een Bierglas ieder keer; maar men moet geen bier drinken, \& geen natte of swaar verteerende spysen 
eeten, \& zig heel warm houden 5 à 6 weeken, drie maal, onder deezen tyd moet den Patient sweeten zegge Purgeeren van 't Extract Catolicum, dit heeft veele geholpen.

Eryngium foetidum L. Snekie-wiwirie. Sack, 1908, p. 14 en in Bulletin van het Departement van den Landbouw, Suriname, 1910 , p. 52 vermeldt het gebruik van een afkooksel der plant tegen verkoudheid.

12. Is een wilde Plant, welke in de boschen groeyt 3 à 4 Voeten hoog; men gebruikt de blaaderen in plats van Spinazie, dewelke bloedreinende is, als men een takkje breekt, komt een wittagtig zap uit, 't word gezegd, dat de Spaniaarden dezelve in Venus quaalen gebruiken, maar op wat manier weete ik niet. de streepen welke langs 't midden van de blaaderen loopen zyn roodagtig, de bloeysels zyn rood.

Lobelia obscura Alm, d.w.z. dat deze Lobelia hem onbekend is. Linnaeus Jr. beschreef deze plant als Lobelia laevigata, wat systematisch Centropogon laevigatus D.C. worden moet. Vermoedelijk is het Centropogon surinamensis Presl (zie A. Pulle, Flora of Surinam, deel IV, p. 303), de eenige uit Suriname bekende soort van dit geslacht.

14. Is een plant of struik genoemd Poppetjes viriviri, is zeer goed om in Clistoeren gebruikt te worden, de bloeysels zyn Pers van Coleur, verdeelt in 5 klyne blaatjes, verbeeldende een klok, met een klyne geele klep in 't midden, onder in zyn deeze bloeysels ook geel; deeze groeyt to 7 à 8 voeten hoogte. De vrugt of zaat zyn eerst groen, ryp geworden bruinagtig, ieder vrugt heeft drie zaaden van binnen.

Jatropha gossypifolia $L$. De naam „poppetjes" schijnt nu niet meer bekend te zijn (Zie de Flora, deel II, p. 66).

16. Is een Plantje Atita genaamd, de bloeysels zyn witt, de hairtjes roodbruin, met geel bruine knoppjes in 't boven eintje, deeze plantje word gebruikt teegen de klyne wurmtjes, welke zig in 't fondament van klyne kinderen gemeenlyk ophouden, de zap word uit deeze blaaderen geperst, \& daarmeede gewassen daar deeze klyne dieren zig ophouden; deeze blaaderen worden ook gekokkt in waater, \& doorgedaan gedronken, verdryven deeze ongediertens schielyk, de stam of steel van deeze plant is rood bruin beneeden by de grond, anders overal groen.

Cleome pentaphylla L. tegenwoordig heetend Gynandropsis pentaphylla D.C. De naam Atieta wordt voor een Rubiacee, Oldenlandia herbacea D.C. opgegeven (zie de Flora, deel IV, p. 127), terwijl deze Cleome eenmaal als Akaja vermeld wordt. 
18. Is een struik, dewelke tot $12 \&$ meerdere voeten hoog op groeyt, de bloeysel is vermillioen rood, met extra mooye geel in de kanten op ieder blad verdeelt in 5 klyne blaatjes van onderen, binnen deeze zitten 4 grootere blaatjes, verbeeldende een opengemaakte waayer, binnen deeze zit nog een klyne blaatje, midden deeze alle zitten 11 hairtjes, $2 \frac{1}{2}$ duim lang, met een roodbruin knoppje, in 't topeinde van elk hairtje, deeze draagt een sort van boontjes, welke zeer sterk afdryvende zyn, \& men gebruikt deze, voor die geenen, welke haar mensis verloren hebben, ja 't word gezegt dat men zelfs de vrugt daarmeede afzetten kan; alzo is zy gevaarlyk in de handen van diegeenen daarmeede quaad wilt doen; men neemt twee handen vol van deeze blaaderen, \& 20 stuks rype boonen of zaaden, de schillen afgenoomen en zet die op een stoop brandewyn in de zon te trekken, 2 maal 24 uuren, getrokken zynde, geeft men aan den Patient 's morgens nukteren een klyne Thee koppje, \& 's avond weeder een, men moet braaf beweeging daarby hebben, op dat men sweeten kan, deeze blaaderen 4 handen vol genoomen \& in een bottel Bier gekookt \& nader doorgedaan en gegeeven om te drinken aan de koebeesten, welke niet kalferen ofwerpen kunnen worden spoedig geholpen.

Poinciana pulcherrima L., tegenwoordig Caesalpinia pulcherrima Sw. geheeten.

21. Is 't blad van een wilde Boon, welke zeer hoog en groot word, deeze boom draagt een vrugt als Pruimen, \& heeft een Extraordinaire \& geprobeerde medicinale kragt by zig, teegen een ziekte welke men tot dato geen secure remedi gevonden, ik kenne deeze Boom, alsmeede de kragt van 't medicyn, \& zal de bloeysel bezorgen mits dat 't geheimer gehouden word als quasia amara, dewelke ik eerst in myn vaderland bekend maakte anno 1754 .

Alm vermeldt dit nummer niet. Dahlberg maakt hier een toespeling op het bekende kwassiehout, waarvoor wij naar de inleiding van dit artikel verwijzen.

24. Is een plantje genoemd Krastayers, men gebruikt de wortels daarvan, fyn geraspt versch zynde, om vuile sweeren te zuiveren $\&$ te geneezen, anders is 't een onkruid die veel werk tot haar uitrooying verschaft, de steel waaraan de bloeysel vast zit, is midden van de bladeren en groeyt tot 10 à 12 duimen hoogte, de bloem is witt \& 't pennetje daar midden is ook witt.

Arum novum Alm. Welke soort van Aracee bedoeld is, is niet uitgemaakt. Volgens Sack, 1910, p. 11, wordt de soort, bekend als Krassi tayer (jeuktayer), niet gegeten, daar alle deelen der 
plant veel raphiden bevatten en ontsteking veroorzaken. 25. Is een rank die zig leunt op andere planten of struiken en groeyt 8 à 9 voeten lang, men gebruikt deeze blaaderen in Venusziektens met een aan No 82 vermengd \& gekookt in waater, 't afkooksel daarvan gedronken drie maal daags, een bierglas vol ieder keer helpt in korten tyd, de bloeysels zyn blauw verdeelt in drie klyne gryze blaatjes van onderen, boven deeze zitten drie extra mooye blauwe blaatjes, verbeeldende een schulp, rond van boven, waarvan twee blaatjes Egal groot zyn, 't derde de helfte klynder, binnen deeze zitten 5 stuks klyne blauwe kliertjes met een klyn geel knoppje in 't boveneinde op ieder hairtje, onder alle deeze zit op een klyne afstand op een steeltje een klyne groene knoppje. Deeze klyne blauwe bloemen, als men die een weinig nat maakt \& op papier vrijft, dan word 't zelve zeer mooy blauw; alzo zoude men daarvan een extra mooye blauwe verf kunnen prepareeren, als men de behandeling daarvan wuste.

Commelina communis $L$. De determinatie zal wel fout zijn, daar deze soort alleen uit Azië bekend is. Misschien is dit Commelina mudiflora $L$. waarvan volgens Sack, 1908, p. 4 en 1910, p. 13, het sap tegen wratten en huiduitslag gebruikt wordt.

29. Is een plant die men noemt Brada bitta viriviri of breede bittere blaaden; de steel groeyt tot 6 voeten hoogte $\&$ heeft op ieder steel drie zulke uitwassingen als hier te zien zyn, rondom deze bolten zitten de bloeysels welke heel bleekrood zyn of oranje rood, deeze blaaderen worden in waater gekookt, deur gedaan zynde geeft men dit waater te drinken aan Neegers die den Jass heeft om die te doen uitslaan, met dit afkooksel wascht men ook de zeeren $\&$ andere uitslag welke daardoor geneest.

Phlomis nepetifolia L. Tegenwoordig Leonotis nepetaefolia $R$. $B r$., Bradi bieta of Ponsoe. Met de Jass of Yaws is de framboesia bedoeld. Zie Sack 1908, p. 15.

31. Is de bloem vrugt \& blaaderen van casoe, deeze struik groeyt tot 14 à 15 voet in hoogten, de bloeysels zyn rood en witt, verdeelt in 5 groene blaatjes van onderen, midden deeze zitten 5 blaatjes de welke zig op de helfte krom ombuigen na buiten, $\&$ spits naboven toe loopende, ieder blaatje is met een witte streepje in 't midden voorzien, \& rood inde kanten, binnen deeze zitten 7 hairtjes, met een klyne knoppje in 't boveneinde, er zyn twee sorten van deeze niets anders in verschillende, als dat d' eene draagt roode $\&$ de andere geele vrugten; de vrugten worden gegeeten, zy zyn zeer adstringeerende \& heeft een aangenaamen reuk, de zaaden of amandelen welke onder aan de 
vrugt vast zitten is zeer lekker om te eeten als men die op 't vuur roostert als Castanjes. De jonge blaaderen van deeze struik worden uitgeperst \& 't zap daarvan gebruikt, om te gorgelen voor de geene welke een zeere keel, of sweeren in de keel hebben voor welke ziekte 't een schoone remedium is.

Anacardium occidentale $L$. Kasjoe. Sack 1908, p. 10, vermeldt hetzelfde als ook het gebruik tegen buikkramp. Zie ook Sack 1910, p. 40 en de Flora, deel II, p. 135.

34. Is de bloeysel vrugt \& blaaderen van een struik Ducat Beursjes genoemd, om reden als men de vrugten opend 't zaat daarin plat \& geel als Ducaten zyn, de bloeysels zyn hoog geel verdeelt eerst in een ronde geele steel, byna twee duimen lang, van binnen holl \& open na beneeden, van boven sluit deeze zig $\&$ formeerd een afhange knoppje \& dan formeert deeze steel de ronte als een klok, buiten klep 1 duim hoog \& 1 do in diameter, heel \& al toe, regt als die gegooten was, dan verdeelt deeze zig in vyfkantige blaatjes, dewelke 1 duim lang \& breed zyn, deeze buigen zig om nabeneeden als een needergeslaagen Hoed, onder deze steeltje zitten 5 klyne blaatjes, spits van boven toeloopende, midden deeze is een klyne knoppje, waar aan de geele steel vast zit, de takken zyn op d'eene zyde bruin \& op de andere zyde groen; de Indianen bruiken de blaaderen daarvan gekookt in waater \& doorgedaan voor Purgaties, men gebruikt dit ook in zogenoemde beljak; als men een tak, blad of vrugt afbreekt, komt zeer veel vogt uit gelykende melk.

Allamanda cathartica $L$. In de Flora, deel IV, p. 10 komt de naam ducaatbeursje niet voor. Sack 1908 p. 14 en 1910 p. 53 vermeldt het gebruik tegen miltaandoeningen.

35. Is de bloeysels vrugt $\&$ blad van een struik of plant Carpata genaamd, de blaaderen daarvan worden gebruikt om op 't hoofd $\&$ voeten vastgebonden te worden op de geenen die zeer ziek zyn om te verkoelen, \& de quaade vogten uit te trekken, men kan een oly van de vrugten prepareeren, dewelke zeer nuttig is in de medicynen als anderzints. Pater Labat schryft zeer omstandig daarvan, de bloeysels van zommige zyn geel als zy uitkoomen, de meeste donkerrood, de aderen of steelen binnen in de blaaderen zyn rood bruin; deeze plant of struik groeyt van 10 tot 12 voeten hoogte.

Ricinus communis L. Krapata, de wonderolie-plant. Zie Sack 1908, p. 10 en 1910 p. 40 en de Flora, deel II, p. 55. Versteeg (zie Lanjouw, The Euphorbiaceae of Surinam, 1931, p. 56) vermeldt, dat de Indianen vandeCottica debladengebruiken tegen hoofdpijn. 
40. Is de vrugt, blaaderen $\&$ bloeysel van de Cujaveboom, de bloeysels bestaat uit 5 witte blaatjes, de hairtjes die midden deeze blaatjes zitten zyn ook witt, deeze boomen groeyt van 25 tot 30 voeten hoogte, zelden regt maar krom van stam, de vrugten zyn aangenaam te eeten, ryp zynde worden zy geel, er zyn 3 soorten, alleen verschillende in groote \& klyndere, zoete \& zuure, als meede dat d'eene rood \& de andere geel, de derde witt van binnen zyn aan de vleesagtige deelen; deeze vrugten zyn verzien met een meenigte van klyne zaaden, zo hard als been, men stooft ook deeze vrugten in suyker, na alvoorens 't zaat uitgenoomen de grootste van deeze vrugten worden ordinaire als een vuist so groot, \& behoud altyd deeze kroon op den appel van onderen, als hier te zien is; de wortelen van de Suure boom word in waater gekookt heel stark, doorgedaan zynde, \& in 't roode als ook in andere loopen, met goed succès gebruikt.

Psidium pyriforme Alm. Bedoeld is Psidium pyriferum L., die Psidium Guajava $L$. heeten moet. Sack, 1908, p. 13 vermeldt het gebruik tegen dysenterie, huidvlekken en maaglijden.

46. Is de bloeysel, blad \& vrugt, van de zogenoemde Terpentyn Boom, maar 't is de Terpentyn Boom niet de bloeysels zyn witt geel, de vrugten ryp zynde worden rood, 't vleesagtige van binnen rondom 't zaat, is als een witte slym, \& heeft een zeer sterke balsamiken reuk \& smaak, hy is ook aankleevend, deeze boomen groeyen zeer hoog, als men in den schors van deeze boom doorkapt, dan komt een schoone witte gom of balzam uit, welke zeer aangenaame reuk heeft, droog zynde kan men die tot Poeyer maaken, men gebruikt dit Poeyer in 't roode Loop, een vingerhoed vol in roode wyn aan den Patient ingegeeven 2, 3 daagen na malkanderen, 't welk van zeer goed effect bevonden is.

Alm vermeldt dit nummer niet. De naam terpentijnboom geeft geen aanwijzing.

59. Is 't blad, bloeysels \& vrugt van de zogenoemde Bebeboom, de knoppjes van 't bloeysel word eerst geel, als de blaatjes opengaan worden zy witt; deeze boomen groeyen meestendeels aan de kanten der revieren of moerassige plaatsen, de wortel van deeze boomen is bruin als flarn of bast van greene boomen, als men die kapt komt een roode zap uit, droog zynde; \& men sneyd eenige klyne spanders van deeze wortel, \& legt die in spiritus of brandewyn, word 't brandewyn schielyk rood van Coleur, den Neeger Quassi zegt, dat een sort van teegengift is.

Pterocarpus ovalis Alm, later door Linnaeus Jr. als Dalbergia Monetaria beschreven. De naam Bebe-boom wordt door den 
laatste goed overgenomen. Alm verhaspelt die tot Bebelan. Met Bébéhoedoe wordt tegenwoordig in Suriname een verwante soort, Pterocarpus Draco L. aangeduid.

65. Is de bloeysels, vrugt \& blaaderen van de Maurici-Boom, de bloeysels zyn brandgeel, de klyne blaatjes midden in zyn witt, de vrugt nadat de bloeysels afgevallen zyn, heeft een aangenaame balzamike reuk \& als men de boom laat omver vallen $\&$ dan 2 à 3 gaaten op de schoors laat kappen, kan men uit deeze stam uittappen 2 à 3 Bottels zap, dewelke zeer zoet $\&$ goed te drinken is, deeze zap heeft een smaak als bier, voor als de hoppen daarop gedaan word, except niet zoo aankleevend aan de lippen, 47 vrugten aan een steel, dewelke lang is 5 voeten $\& 39$ stuks zulke steelen met vrugten aan weerskanten van de tak of hand, alle deeze met malkanderen maaken een figure uit als een druiftross, deeze tak groeyt uit den stam tusschen de andere takken, die met lange blaaderen voorzien zyn, verbeeldende een Pauwstaart of een dubbelde waayer, de tak met vrugten heeft geene blaaderen, maar makt een zeer grooten druiven bos uit waarin 1833 stuks vrugten zig bevinden, deeze vrugten worden eerst geel, nader brandgeel, ryp zynde glensend bruin; deeze boom dat ik heb laaten omver kappen was 77 voeten buiten de kroon dewelke uit 12 takken met blaaderen bestaat, de stam groeyt lyn regt, $\&$ perpendiculaire op \& dik in diameter drie voeten, hebbende een harde schors dik een duim, van binnen is de stam opgevuld, met een sort van merg of zagt draadigheid, de Takken zyn op een vierde deel omgeboogen na boven open, formeerend een gooter, smaalder na de kant van de blaaderen toeloopende een hand breed. van de blaaderen is de tak heel rond, de blaaderen zyn 5 voeten lang, spits na boven toeloopende, boven in 't topeinde van deeze boom groeyt een sort van kol, die hier genoemd word babbefi, dewelke zeer goed te eeten is als die met booter $\&$ specereyen gestoofd word men kan deeze kol ook in assyn \& specereyen inleggen, om lang bewaard te worden, om met gebraad te eeten, 't groeyt ook in deeze boomen een soort van wurmen babbesi wurmen genoemd; veele menschen eeten deze wurmen, nadat ze in de Pan gebakken word met booter, deeze wurmen worden torren, welke koomen haar voedsel in 't binnenste van deeze boom zoeken, deeze leggen dan haare Eyeren daarin, $\&$ na verloop van 3 weeken komt uit deeze Eyeren wormen voort, grooter geworden zynde krygen zy vlerken $\&$ pooten $\&$ dan verlaaten zy haar Logies \& gaan na een andere boom haar voedsel zoeken, na alvoorens alles in deeze boom dienlyk tot haar voedsel 
opgegeeten te hebben, iedere tak heeft 218 stuks blaaderen; Pater Labat zegt dat deeze wormen in de zon gedistilleerd tot een oly zeer goed zal zyn om te gebruiken tegens de jicht; ik heb wat van deeze oly bewaard, \& dezelve op myselfs geappliceert $\&$ goed bevonden.

Niet in Alm vermeld. Door Linnaeus Jr. Mauritia flexuosa genoemd. Het is de bekende Maurisie-palm. Zie Sack, 1910, p. 9.

70. Is 't blad, vrugt \& bloeysels van een struik, dewelke nooten of amandelen draagt Purgatienooten genoemt deeze groeyt van 10 à 12 voeten in hoogte, in ieder noot zyn drie amandelen, de bloeysels zyn bleekgroen, stootende op witt, verdeelt in 2 verdiepingen, in 5 blaatjes van onderen $\& 5 \mathrm{~d}^{\circ}$ van boven, welke een weinig langer zyn als de onderste \& een weinig na buiten omgeboogen, midden in deeze bovenste zitten 9 hairtjes of stippeltjes, welke geelagtig zyn, de vrugt ryp zynde is geel, droog geworden swart, men neemt van deeze amandelen 5 à 7 stuks tot een Purgatie, na alvoorens 't witte vlies welke om de amandelen zit weggenoomen te hebben, alzo deeze vlies veel snyding $\&$ pyn in de ingewanden veroorzaakt; deeze amandelen purgeeren $\&$ vomeeren \& smaaken niet onaangenaam.

Jatropha Curcas L., schijtnoten, zie Sack, 1910, p. 37 en de flora, deel II, p. 68.

82. Is een plantje welke platt op de grond neederlegt, deeze plantje word gebruikt in Venus ziektens met No. 25, vier handen vol van ieder \& zamen gekookt in 2 stoop waater tot een, men kan daarbij doen een weinig malasie of siroop, om 't smaakelyker te maaken, dit doorgedaan zynde, geeft men 't aan den Patient, 3 maal daags te drinken, een bierglas vol ieder keer, tot de geneezinge toe, men geeft ook een Purgatie of twee onder deeze tyd, den Patient dient goede diête te houden, zig wagten voor veel zout \& zuur, dan word men in korten tyd geneezen, als men 't van deeze klyne steeltjes of blaadjes breekt komt een witte vogt als melk uit, de bloeysels zyn bruinagtig.

Euphorbia canescens $L$. De determinatie is zeker onjuist, want deze soort behoort aan de Middellandsche zee thuis. Vermoedelijk is Euphorbia thymifolia L. bedoeld. Zie Sack, 1908, p. 10 en de recepten in Lanjouw, p. 65.

88. Is 't blad, vrugt \& bloeysels van een plant of struik Slaapers genoemt, groeyt tot 7 à 8 voeten hoogte, de bloeysels zyn brandgeel, verdeelt in 5 groene blaatjes van onderen spits toeloopende naboven, boven deeze zitten 5 brandgeele ofhange blaatjes, binnen deeze 5 zit een groene steeltje, op de zyde van 
deeze midden in de bloem zitten 7 stuks klyne hairtjes, met een afhange klyne knoppje van boven verzien, deeze hairtjes zyn groen geel, ieder takkje heeft 6 blaaderen, \& 23 zulke takkjes op eenen tak, deeze struik of plant draagt een sort van boontjes, waarin de zaaden bewaard worden, men neemt 3 à 4 handen vol van deeze blaaderen \& kookt die in reegenwaater, \& met dit waater de geenen welke de koors hebben gewaschen, is zeer goed $\&$ breekt die koors, men neemt ook deeze blaaderen, na alvoorens dezelve op koolen vlauwgemaakt te hebben, \& dan op zeeren gelegt, op de geene die zulks hebben zuiveren dezelve \& bevordert de geneezing.

Cassia Tora L. Merian vermeldt in het boek over de Surinaamsche insecten bij plaat 32 de naam Slaapertjes.

102. Is 't blad, bloeysel \& vrugten van een struik, men noemt haar ringvormboom, alzo men met 't zap de ring vorm geneest, men neemt 't bast van de stam of takken af, \& krabt 't roode zap welke tusschen 't bast $\&$ de stam zit af, \& smeert op de ringvormen eenige daagen agter aan, dan verdwijnt of gaat de ringvormen heel \& al weg, de bloeysels zyn geel, verdeelt in 5 groene blaatjes van onderen, spits toeloopend na boven, binnen deeze zitten 5 stuks geele blaatjes, veel grooter als de onderste \& rond van boven, \& in de hoogte regt opstaande, van binnen op de blaatjes, met veele klyne witte hairtjes bezet, binnen deeze zitten 5 klyne witte steeltjes, van boven platt rond, met een meenigte klyne witte hairtjes, rondom 't plattronde, \& op ieder hairtje een klyn gryze knoppje, de vrugten zyn roodbruin.

Hypericum aliud Alm. Bij Linnaeus Jr. Hypericum bacciferum genoemd. Welke Vismia-soort bedoeld is, is niet zeker, zie de flora, deel III, p. 72 en vlgg. en P. J. Eyma, The Polygonaceae, Guttiferae and Lecythidaceae of Surinam, I932 p. 88 en 89. Volgens de Encyclopaedie van Ned. W. Indië bedoelde Fermin in 1764 met zijn twee soorten van ringworm andere huidaandoeningen dan die men tegenwoordig zoo noemt.

106. Is een plantie welke op sandig land groeyt tot 2 voeten hoogte, als men de takkies of blaaderen tusschen de handen vryft, ruiken zy als Camphert, de bloeysels verdeelen zig in 2 klyne ruige blaatjes van onderen, spits toeloopend van boven, boven deeze zitten 4 stuks klyne groene knoppjes, met een klyne geele blaatje van boven, op ieder knoppje, midden deeze zitten 4 klyne hairen, met een klyne knoppje in 't boveneinde; de Neegers gebruiken deeze Plant om zig daarmeede te doen sweeten als zy verkouwt geworden zyn, of pyn in de rug \& bonken hebben, zy 
kooken dan een party van deeze in waater, \& zetten zig well toegedekt over 't heete waater, \& vryven zig met deeze plantje overal daar zy de pyn voelen, waardoor zy stark sweeten, \& daardoor gaat de pyn weg. Ik weete de naam niet, als men na de reuk zoude oordeelen, dan zou men dezelve 't Campherplantje noemen.

Unxia camphorata L. Tegenwoordig Melampodium camphoratum Bth. \& Hook geheeten, kamferbladen.

127. Is 't blad \& bloeysels van nog een struik, de bloeysels begint eerst in een zeer klyne witte steeltje waarop zit een witte kooker, lang een duim, boven deeze zit een witte blomknop, spits naboven toeloopende, als die opengaat verdeelt hy zig in 5 witte blaatjes een duim lang, \& ovaal rond van boven, spits toeloopend nabeneeden, als men de tak of de blom afbreekt, komt een meenigte zap uit, zo witt als melk, men neemt een party van deeze blaaderen \& takken \& kookt die in twee stoopen waater tot een, \& men legt daarby een stuk afgebrande Eyzer, of smeedslag, als dit by elkander gekookt is dan doet men 't door een doek \& roerd een weinig stroop daarbij, om 't smaakelyker te maaken, deeze drank word dan gegeeven aan diegeene welke Venusziektens hebben, een Bierglas 's morgens \& een dito 's avonds; dit helpt in korten tyd.

Echites nova Alm, later door Linnaeus Jr. als Echites syphilitica beschreven. Welke soort hiermee bedoeld wordt, is niet bekend, zie de flora, deel IV.

136. Is een soort van riet, welke op een steel met leeden groeyt, tot 9 voeten hoogte met 21 stuks blaaderen omgewaschen van boven hebbende in den topeinde een roode vrugt of bloeysels gelykende haast de vrugten welke aan de greene boomen groeyt, als dit riet eerst opkomt uit d'aarde, ziet 't uit als de doorgesneedene steel, welke ook in 't stoop te zien is; de Neegers gebruiken deeze bloeysel of vrugten voor 't vlees op de oogen, zy drukken 't zap daaruit $\&$ laat in 't oogen druipen, 3 à 4 droppels, 's morgens \& 's avonds, eenige daagen lang, \& zy zeggen dat dit hun volkoomelyk hersteld.

Costus arabicus L. Deze soort behoort in Oost-Azië thuis, zoodat de determinatie niet juist kan zijn. Sack 1908, p. 5 vermeldt, dat het sap van Costus spec. (sangrafoe) gebruikt wordt tegen kriebeling in de keel.

153. Is 't blad \& bloeysels van een rank gewass, welke zig op andere gewassen leunt, de bloeysels beginnen eerst in groene knoppies, open gegaan zynde verdeelt deeze zig in 2 klyne blaatjes, midden deeze zitten 4 witte kookertjes, wyder na boven als 
beneeden, dewelke zig ieder van boven verdeelt in 5 klyne kantjes of taggies, binnen deeze zit een klyn zwart steeltje in ieder kookertje, in 't topeinde hebbende twee kromgeboogene witte hairtjes, de blaaderen van deeze rank, 4 à 5 handen vol, worden in waater gekookt tot op de $\frac{1}{2}$ te van 't waater, doorgedaan zynde geeft men 1 bierglas vol, 3 maal 's daags, 1 dag of 3 aan de geenen haar mensis verlooren hebben, dan worden zy hersteld; men gebruikt dit ook in Venusziektens; maar dan wordt 't sterker gekookt \& men continueerd daarmeede tot de geneezinge toe.

Cactus triangularis L. Tegenwoordig Cereus triangularis Haw geheeten.

Van deze soorten worden er vier koortswerend genoemd (nrs. $6,9,35$ en 88), twee zweetdrijvend (nrs. 8 en 106), vijf tegen venerische ziekten (nrs. 12, 25, 82, 127 en 153), twee tegen menstruatiestoringen (nrs. 18 en 153), drie purgeerend (nrs. 14, 34 en 70), twee tegen roode loop (nrs. 40 en 46), de overige ziekten worden elk maar één keer genoemd, nml. aarswormen (16), framboesia (29), zeere keel (31), zweeren (24), een niet genoemde ziekte (21), belliac (34), vergift (59), jicht (65), ringworm (102), oogziekte (136) en lumbago (106). 